\title{
SILAGENS DE GIRASSOL (Helianthus annus L.), MILHO (Zea mays L.) E SORGO (Sorghum bicolor (L.) Moench) PARA OVELHAS EM CONFINAMENTO
}

\author{
SILAGES OF SUNFLOWER (Helianthus annus L.), CORN (Zea mays L.) \\ AND SORGHUM (Sorghum bicolor (L.) Moench) FOR EWES IN FEEDLOT
}

\author{
Edson Luis de Azambuja Ribeiro ${ }^{1}$ Marco Antonio da Rocha ${ }^{2}$ \\ Ivone Yurika Mizubuti ${ }^{2}$ Leandro das Dores Ferreira da Silva ${ }^{3}$
}

RESUMO

Este trabalho teve como objetivo avaliar o desempenho de ovelhas recebendo silagens de milho, sorgo e girassol. Metade da matéria seca da dieta foi fornecida pelas silagens e a outra metade por uma mistura de $25 \%$ de farelo de soja e $75 \%$ de milho grão. Foram utilizadas 47 ovelhas confinadas por um período de 70 dias. As ovelhas que receberam silagem de girassol ganharam mais $(P<0,01)$ peso diariamente $(0,263 \mathrm{~kg})$ do que as que receberam silagens de milho $(0,175 \mathrm{~kg})$ ou sorgo $(0,171 \mathrm{~kg})$. Os consumos de alimento, tanto como percentagem do peso vivo, quanto por unidade de tamanho metabólico, diferiram entre os tratamentos $(P<0,01)$, sendo maiores pelos animais tratados com silagem de milho, intermediário com silagem de girassol e menores com aqueles com silagem de sorgo. As conversões alimentares foram de 7,96; 7,26 e $6,14(P>0,05)$, respectivamente, para ovelhas recebendo silagens de milho, sorgo e girassol. As ovelhas alimentadas com silagem de girassol apresentaram maior percentagem de carcaça quente $(53,14 \%)$ do que aquelas com silagem de sorgo $(48,13 \%)$ ou com silagem de milho (46,36\%). Portanto, a silagem de girassol é superior às silagens de milho e sorgo na terminação de ovinos confinados.

Palavras-chave: carcaça, conversão alimentar, ganho de peso, girassol, ovinos, silagem.

\section{SUMMARY}

The objective of this paper was to evaluate the performance of ewes receiving corn, sorghum or sunflower silages. Half of the dry matter diet came from the silages and the other half from a concentrate, $25 \%$ of soybean meal and $75 \%$ of ground corn. Forty-seven ewes were used and confined during a period of 70 days. Ewes receiving sunflower silage had a greater $(P<0.01)$ daily weight gain $(0.263 \mathrm{~kg})$ than ewes receiving corn
$(0.175 \mathrm{~kg})$ or sorghum $(0.171 \mathrm{~kg})$ silages. Feed consumption, as a percentage of the body weight $(B W)$ or per unit of metabolic body weight $\left(B W^{0.75}\right)$, were greater $(P<0.01)$ for ewes receiving corn silage, intermediate for ewes receiving sunflower silage and lower for ewes receiving sorghum silage. Feed conversion were 7.96, 6.14 and 7.26 (P>0.05), respectively, for ewes receiving corn, sunflower and sorghum silages. Ewes fed sunflower silage showed greater percentage of hot carcass $(53.14 \%)$ than the ewes fed sorghum $(48.13 \%)$ or corn $(46.36 \%)$ silages. It can be concluded that the sunflower silage is better than corn and sorghum silages for termination of feedlot sheep.

Key words: carcass, feed conversion, sheep, silage, sunflower, weight.

\section{INTRODUÇÃO}

A terminação de animais ruminantes em confinamento é uma opção viável quando há alimentos volumosos disponíveis a baixo custo, e/ou durante o período de entressafra. $\mathrm{O}$ confinamento com ovinos também tem sido recomendado por possibilitar menor mortalidade e menor custo com vermífugos, bem como maior ganho de peso, e principalmente, maior lucro final (SIQUEIRA $\boldsymbol{e t}$ al., 1993; MACEDO et al., 2000).

Para o desempenho desejável dos animais confinados, há a necessidade de uma alimentação de boa qualidade. $\mathrm{O}$ uso de ensilagens para a alimentação de animais nos períodos de carência de pastagens, bem como para a engorda de animais tem se tornado prática comum entre os pecuaristas. $\mathrm{O}$

${ }^{1}$ Zootecnista, PhD. Universidade Estadual de Londrina (UEL), Centro de Ciências Agrárias (CCA), Departamento de Zootecnia, CP 6001, 86051-990, Londrina, PR, Brasil. E-mail: elar@uel.br. Autor para correspondência.

${ }^{2}$ Médico, Veterinário, Doutor. UEL, CCA, Departamento de Zootecnia.

${ }^{3}$ Zootecnista, Doutor. UEL, CCA, Departamento de Zootecnia. 
milho (Zea mays L.) é a espécie forrageira mais utilizada para esta finalidade. Entretanto, outras culturas, por se adaptarem as condições climáticas e de solo menos favoráveis, têm sido recomendadas, como o sorgo (Sorghum bicolor (L). Moench) e o girassol (Helianthus annus L.) (ALMEIDA et al., 1995; GENRO et al., 1995).

O cultivo do girassol no Brasil vem se expandindo, porém o seu uso é mais restrito à produção de grãos para a extração de óleo. Os subprodutos desta extração têm sido utilizados na alimentação na forma de farelos (MANDARINO, 1992). O uso de silagem de girassol na alimentação de animais ruminantes é antiga (SCHAFER \& WESTLEY, 1921), porém no Brasil o seu uso é ainda limitado. No que diz respeito à qualidade das silagens, a de girassol é similar à silagem de milho (ALMEIDA et $\boldsymbol{a l} .$, 1995), sendo a de sorgo similar ou um pouco inferior a de milho (ALMEIDA et $\boldsymbol{a l}$., 1995; GENRO et al., 1995).

Levando em consideração o exposto acima e o fato de os dados de desempenho com ovinos alimentados com silagem de girassol no Brasil serem inexistentes ou raros, este trabalho teve como objetivo avaliar o ganho de peso, a conversão alimentar e os componentes do peso vivo de ovelhas confinadas que receberam como fonte volumosa silagens de milho, sorgo e girassol.

\section{MATERIAL E MÉTODOS}

O experimento foi conduzido na Fazenda Escola da Universidade Estadual de Londrina, Londrina, Paraná. Foram utilizadas 47 ovelhas adultas da raça Hampshire Down confinadas durante um período de 70 dias, a partir de primeiro de setembro. O confinamento consistia de três baias em um aprisco coberto, com piso ripado e elevado do chão. No início do experimento, os animais foram everminados com anti-helmíntico de amplo espectro. Utilizou-se o delineamento experimental inteiramente casualizado, onde os animais foram aleatoriamente divididos em três lotes, sendo que cada lote recebeu um tipo de silagem (milho, sorgo ou girassol). Na confecção das silagens, o milho e o sorgo encontravam-se no estádio de grãos farináceos, e o girassol no início da maturação fisiológica (grãos leitosos).

As dietas foram preparadas para conterem $50 \%$ de silagem e $50 \%$ de concentrado, na base da matéria seca. O concentrado era composto de $25 \%$ de farelo de soja e $75 \%$ de grão de milho. Os valores encontrados para matéria seca (MS), proteína bruta (PB) e nutrientes digestíveis totais (NDT) dos alimentos e das dietas finais (silagem de girassol + ração concentrada, silagem de sorgo + ração concentrada e silagem de milho + ração concentrada) são apresentadas na tabela 1. As percentagens de NDT foram calculadas de acordo com fórmula sugerida por McDOWELL et al. (1974), que leva em consideração os teores de fibra bruta, extrato etéreo, proteína bruta e extrativo- nãonitrogenado nos alimentos. As rações completas foram fornecidas ad libitum, sendo distribuídas nos cochos duas vezes ao dia, descartando-se as sobras. Os animais também tiveram livre acesso a sal mineralizado e água.

Os animais foram pesados individualmente no início do experimento e posteriormente a cada 14 dias até o final do mesmo. As conversões alimentares, em função do consumo total de alimentos pelos animais em cada período e dos ganhos de peso em períodos de 14 dias, foram calculadas para cada lote. No final do período de confinamento, cinco ovelhas de cada tratamento foram aleatoriamente abatidas. Determinou-se, nesses animais, o peso vivo imediatamente antes do abate, bem como o peso da carcaça quente, pele, cabeça, canela e patas, trato digestivo vazio, pulmão e traquéia, fígado, rins, coração, baço e gordura cavitária. Os dados foram submetidos à análise de variância tendo como única variável independente o efeito de tipo de silagem. As diferenças entre médias foram comparadas pelo teste t, opção PDIFF no procedimento GLM do SAS (SAS INSTITUTE, 1989).

\section{RESULTADOS E DISCUSSÃO}

$\mathrm{Na}$ tabela 2, são apresentadas as médias para pesos iniciais e finais, bem como para os ganhos de peso médio diário no período total do confinamento. No início do experimento, os pesos

Tabela 1 - Percentagens de matéria seca (MS), proteína bruta (PB) e nutrientes digestíveis totais (NDT) dos alimentos e das dietas utilizadas.

\begin{tabular}{lccc}
\hline Alimentos & MS (\%) & PB (\%) & NDT $(\%)^{1}$ \\
\hline Silagem girassol (SG) & 18,93 & 8,02 & 74,02 \\
Silagem sorgo (SS) & 27,78 & 4,78 & 63,59 \\
Silagem milho (SM) & 33,67 & 7,55 & 72,16 \\
Milho grão & 88,00 & 10,57 & 90,91 \\
Farelo de soja & 89,00 & 50,56 & 82,02 \\
Dietas & & & \\
SG + Ração concentrada & 53,59 & 14,29 & 81,35 \\
SS + Ração concentrada & 58,02 & 12,67 & 76,14 \\
SM + Ração concentrada & 60,96 & 14,06 & 80,42 \\
\hline
\end{tabular}

${ }^{1}$ Em base seca. 
Tabela 2 - Médias e erros padrões para pesos, ganhos de peso médio diário (GMD), consumo de alimentos por unidade de tamanho metabólico (UTM) e em relação a percentagem do peso vivo (PV) e conversão alimentar (consumo em $\mathrm{kg} / \mathrm{GMD}$ ) segundo as diferentes silagens.

\begin{tabular}{lllll}
\hline Variável & $\begin{array}{l}\text { Silagem } \\
\text { girassol }\end{array}$ & Silagem sorgo & Silagem milho & Pr. > F \\
\hline Peso inicial, kg & $41,07 \pm 1,92 \mathrm{a}$ & $40,07 \pm 2,02 \mathrm{a}$ & $41,80 \pm 1,97 \mathrm{a}$ & 0,7868 \\
Peso final, kg & $59,49 \pm 1,91 \mathrm{a}$ & $52,04 \pm 2,01 \mathrm{~b}$ & $54,03 \pm 1,95 \mathrm{~b}$ & 0,0156 \\
GMD, kg & $0,263 \pm 0,014 \mathrm{a}$ & $0,171 \pm 0,015 \mathrm{~b}$ & $0,175 \pm 0,014 \mathrm{~b}$ & 0,0001 \\
Consumo-UTM, g & $76,75 \pm 2,00 \mathrm{~b}$ & $69,75 \pm 2,00 \mathrm{c}$ & $83,25 \pm 2,00 \mathrm{a}$ & 0,0034 \\
Consumo-PV, \% & $2,90 \pm 0,07 \mathrm{~b}$ & $2,63 \pm 0,07 \mathrm{c}$ & $3,15 \pm 0,07 \mathrm{a}$ & 0,0019 \\
Conversão & $6,14 \pm 0,82 \mathrm{a}$ & $7,26 \pm 0,82 \mathrm{a}$ & $7,96 \pm 0,82 \mathrm{a}$ & 0,3288 \\
\hline
\end{tabular}

a,b,c Médias seguidas por letras diferentes diferem entre si.

dos animais não apresentaram diferenças significativas, porém após 70 dias de confinamento, as ovelhas que receberam como fonte volumosa a silagem de girassol, pesaram em média $9 \%$ e $12 \%$ a mais $(\mathrm{P}<0,05)$ que as ovelhas que receberam silagens de milho e sorgo. O ganho de peso diário foi em média $34 \%$ maior $(\mathrm{P}<0,01)$ para as ovelhas que receberam silagem de girassol do que para as ovelhas que receberam as outras silagens. Como observado na tabela 1 , as silagens de girassol e milho tiveram composição em energia e proteína bastante próximas, o que concorda com ALMEIDA et al. (1995). Estes autores encontraram teores de proteína um pouco maior na silagem de girassol do que o valor encontrado neste trabalho. Pela composição observada, era de se esperar ganhos de peso similares, o que concorda com McGUFFEY \& SCHINGOETHE (1980), que observaram produções de leite similares em vacas Holandesas alimentadas com estas duas silagens.

Outros fatores ligados à composição e digestibilidade devem ter influído no maior ganho de peso nas ovelhas alimentadas com silagem de girassol. Em trabalho conduzido paralelamente a este, avaliando a digestibilidade dos componentes destas silagens, MIZUBUTI et al. (2000) verificaram um maior consumo de extrato etéreo (9,55 $\left.\mathrm{g} / \mathrm{kg}^{0,75} / \mathrm{dia}\right) \quad \mathrm{em}$ ovinos alimentados exclusivamente com silagem de girassol, bem como uma maior digestibilidade aparente $(92,07 \%)$ desta fração, do que em animais alimentados com silagem de milho $\left(3,69 \mathrm{~g} / \mathrm{kg}^{0,75} / \mathrm{dia}\right.$ e $\left.82,57 \%\right)$. Os autores não observaram outras diferenças importantes entre estas duas silagens. Apesar de uma menor qualidade aparente da dieta incluindo silagem de sorgo, comparado com a dieta contendo silagem de milho (tabela 1), bem como observado por MIZUBUTI $\boldsymbol{e} t$ al. (2000), uma menor digestibilidade e consumo da fração extrato etéreo $\left(64,70 \%\right.$ e $2,43 \mathrm{~g} / \mathrm{kg}^{0,75} / \mathrm{dia}$, respectivamente), e menor consumo das frações matéria seca e proteína bruta por animais recebendo silagem de sorgo, não houve diferença no peso final e no ganho de peso médio diário entre as ovelhas alimentadas com estas duas silagens. Os ganhos de peso das ovelhas recebendo silagem de girassol estão coerentes com as recomendações do NRC, segundo CAMPOS (1995), porém os ganhos das ovelhas recebendo silagens de milho ou sorgo, estão aquém do esperado.

As médias para consumo de alimentos e para conversão alimentar são apresentadas na tabela 2. Os consumos de alimentos, como percentagem do peso vivo e por unidade de tamanho metabólico, foram maiores $(\mathrm{P}<0,01)$ nos animais alimentados com silagem de milho, intermediário nos animais tratados com silagem de girassol e menores com aqueles que receberam silagem de sorgo. Porém, não houve diferença significativa entre as conversões alimentares para as dietas estudadas. Os consumos observados neste experimento estão dentro do esperado para ovinos adultos confinados, estando próximos daqueles observados por PILAR et al. (1994). Porém, os consumos de matéria seca foram maiores que os observados por ALMEIDA et al. (1995), sendo que estes autores observaram consumos similares entre silagens de girassol e milho, e consumo menor para silagens de sorgo. Por outro lado, McGUFFEY \& SCHINGOETHE (1980) observaram menor consumo de matéria seca para vacas leiteiras recebendo silagem de girassol do que nas alimentadas com silagem de milho.

$\mathrm{Na}$ tabela 3, são apresentadas os pesos médios dos animais abatidos e dos componentes do peso vivo. Os pesos no momento do abate foram muito próximos do peso dos lotes, sendo que aproximadamente $30 \%$ das ovelhas confinadas foram abatidas. Este resultado mostra que os lotes eram bastante uniformes. As ovelhas que receberam silagem de girassol apresentaram um rendimento de carcaça quente maior $(\mathrm{P}<0,01)$ do que as que receberam silagens de sorgo ou milho, 53,14, 48,13 e $46,36 \%$, respectivamente. Este resultado, provavelmente, ocorreu em função das menores $(\mathrm{P}<0,05)$ percentagens de cabeça e canela-patas apresentadas pelas ovelhas que consumiram silagem de girassol, bem como, menor $(\mathrm{P}>0,05)$ percentagem de aparelho digestivo vazio.

As diferenças estatísticas observadas para as percentagens de pulmão-traquéia, fígado e baço, entre os tratamentos não têm uma explicação clara. De uma maneira geral, as percentagens dos componentes do peso vivo estão de acordo com a 
literatura (PILAR et al., 1994, OSÓRIO et al., 1996a,b; RIBEIRO et al., 2000), cabendo salientar que a percentagem de carcaça quente $(53,14 \%)$ observada nas ovelhas que foram alimentadas com silagem de girassol, é maior do que as observadas pelos autores citados. Rendimento de carcaça acima de $50 \%$ em ovinos só é obtido em animais confinados e geneticamente superiores.

\section{CONCLUSÕES}

$\mathrm{O}$ uso da silagem de girassol como fonte única de volumosos pode ser uma ótima opção para a engorda de ovinos, pois ovelhas alimentadas com esta silagem apresentaram maiores ganhos de peso e rendimentos de carcaça do que ovelhas alimentadas com silagens de milho e sorgo. Não houve diferenças no desempenho de ovelhas alimentadas com silagens de milho ou sorgo.

\section{REFERÊNCIAS BIBLIOGRÁFICAS}

ALMEIDA, M.F., de, TIESENHAUSEN, I.M.E.V.V., AQUINO, L.H., de, et al. Composição química e consumo voluntário das silagens de sorgo, em dois estádios de corte, girassol e milho para ruminantes. Ciência e Prática, Lavras, v.19, n.3, p.315-321, 1995 .

CAMPOS, J. Tabelas para cálculo de rações. Viçosa Universidade Federal de Viçosa - Imprensa Universitária, 1995. 64p.

GENRO, T.C.M., QUADROS, F.L.F., de, COELHO, L.G.M., al. Produção e qualidade de silagens de híbridos de milho (Zea mays) e de híbridos de sorgo (Sorghum bicolor). Ciência Rural, Santa Maria, v.25, n.3, p.461-464, 1995.

MACEDO, F.A.F., SIQUEIRA, E.R., MARTINS, E.N. Análise econômica da produção de carne de cordeiros sob dois sistemas de terminação: Pastagem e confinamento. Ciência Rural, Santa Maria, v.30, n.4, p.677-680, 2000.

MANDARINO, J.M.G. Características bioquímicas e nutricionais do óleo e do farelo de girassol. Londrina : EMBRAPA - CNPSo, 1992. 25p. (Documentos, 52)

McDOWELL, L.R., CONRAD, J.H., THOMAS, J.E., et al. Tabelas de composição de alimentos da América Latina Gainesville : Universidade da Flórida, 1974. 63p.

McGUFFEY, R.K., SCHINGOETHE, D.J. Feeding value of a high oil variety of sunflowers as silage to lactating dairy cows. Journal of Dairy Science, v.63, p.1109-1113, 1980.
MIZUBUTI, I.Y., RIBEIRO, E.L.A., ROCHA, M.A., $\boldsymbol{e t} \boldsymbol{a l}$. Avaliação nutricional das silagens de milho (Zea mays L.), sorgo (Sorghum bicolor L.) Moench) e girassol (Helianthus annus L.) para uminantes. In: REUNIÃO ANUAL DA SOCIEDADE BRASILEIRA DE ZOOTECNIA, 37, 2000, Viçosa, MG. Anais... Viçosa : Sociedade Brasileira de Zootecnia, 2000. CD-Rom.

OSÓRIO, J.C., OLIVEIRA, N.M., JARDIM, P.O., et al. Produção de carne em ovinos de cinco genótipos: 2. Componentes do peso vivo. Ciência Rural, Santa Maria, v.26, n.3, p.471-475, 1996a.

OSÓRIO, J.C., JARDIM, P.O., PIMENTEL, M., et al. Componentes do peso vivo em cordeiros da raça Corriedale. Ciência Rural, Santa Maria, v.26, n.3, p.483487, 1996b.

PILAR, R.C., PIRES, C.C., RESTLE, J., et al. Desempenho em confinamento e componentes do peso vivo de diferentes genótipos de ovinos abatidos aos doze meses de idade. Ciência Rural, Santa Maria, v.24, n.3, p.607-612, 1994.

RIBEIRO, E.L.A.R., ROCHA, M.A., MIZUBUTI, I.Y., et al. Ganho de peso e componentes do peso vivo em borregos Ile de France inteiros ou castrados e Hampshire Down castrados abatidos aos doze meses de idade. Ciência Rural, Santa Maria, v.30, n.2, p.333-336, 2000 .

SAS INSTITUTE. SAS/STAT User's guide. Version 6. 4 ed. Cary : SAS Institute, 1989. V.2, 846p.

SCHAFER, E.G., WESTLEY, R.O. Sunflower production for silage. Pullman : State College of Washington, 1921. 20p. (Bulletin, 162).

SIQUEIRA, E.R., AMARANTE, A.F.T., FERNANDES, S Estudo comparativo da recria de cordeiros em confinamento e pastagem. Veterinária e Zootecnia, São Paulo, v.5, p.17-28, 1993. 